\title{
The Role of Computed Tomography in the Assessment of Blunt Bowel and Mesenteric Injuries
}

\author{
Nguyen Duy Hung ${ }^{1,2 \dagger}$, Hoang Duc Ha ${ }^{3 \dagger}$, Vuong Kim Ngan ${ }^{2}$, Than Van Sy ${ }^{2}$, Le Thanh Dung ${ }^{2}$, Nguyen Minh Duc ${ }^{4,5^{\circ}}$
}

${ }^{1}$ Department of Radiology, Hanoi Medical University, Hanoi, VIETNAM

${ }^{2}$ Department of Radiology, Viet Duc Hospital, Hanoi, VIETNAM

${ }^{3}$ Department of Radiology, Haiphong University of Medicine and Pharmacy, Hai Phong City, VIETNAM

${ }^{4}$ Department of Radiology, Pham Ngoc Thach University of Medicine, Ho Chi Minh City, VIETNAM

${ }^{5}$ Department of Radiology, Children's Hospital 2, Ho Chi Minh city, VIETNAM

t: These authors contributed equally to this article

*Corresponding Author: bsnguyenminhduc@pnt.edu.vn

Citation: Duy Hung N, Duc Ha H, Kim Ngan V, Van Sy T, Thanh Dung L, Minh Duc N. The Role of Computed Tomography in the Assessment of Blunt Bowel and Mesenteric Injuries. Electron J Gen Med. 2020;17(5):em242. https://doi.org/10.29333/ejgm/8208

ARTICLE INFO

Received: 22 Mar. 2020

Accepted: 10 Apr. 2020

\section{ABSTRACT}

Background: Bowel and mesenteric injuries have high morbidity and mortality rates in the trauma group due to non-specific symptoms and are often obscured in the context of multiple traumas, contributing to an increased risk of peritonitis and sepsis. The purpose of this research was to assess the diagnostic accuracy of 16-slice multidetector computed tomography (MDCT) findings in the diagnosis of bowel and mesenteric injuries accompanied by the association of these findings with the treatment strategy.

Methods: A retrospective study was performed on 86 blunt-abdominal-trauma patients, hospitalized at the emergency department of our institution from June 2018 to July 2019 (75 men and 11 women aged 4-76 years old with a median age of 40.88), who had 16-slice MDCT diagnosis of blunt bowel and mesenteric injuries and were treated by nonsurgical and surgical treatment. Ethical clearance was taken from the institute ethics committee with waiver of consent.

Results: The specificity of bowel-wall rupture, active extravasation, and reduced bowel-wall enhancement were $100 \%, 98.15 \%$, and $100 \%$, respectively. Pneumoperitoneum had the highest sensitivity of $83.33 \%$. Bowel-wall rupture, Janus signs, pneumoperitoneum, and mesenteric stranding were significantly correlated with surgical results. The existence of these results improved the likelihood of 7-, 6-, 29- and 3-fold surgical treatment, respectively. Inter-observer consensus was very strong for bowel-wall rupture, active extravasation, bowel hematoma, and pneumoperitoneum.

Conclusion: Bowel-wall rupture was the definite sign of bowel injury and its connection with surgical treatment was important. Pneumoperitoneum was not a specific indication of blunt bowel injury; but when this is detected, emergency intervention should be suggested.

Keywords: bowel injuries, mesenteric injuries, computed tomography, surgery

\section{INTRODUCTION}

Blunt bowel and mesenteric injuries account for $1 \%$ of emergency trauma injuries and $1 \%-5 \%$ of blunt abdominal trauma, of which over $50 \%$ of cases are small bowel injuries $(1,2)$. Bowel and mesenteric injuries have high morbidity and mortality rates in the trauma group due to non-specific symptoms and are often blurred in the context of multiple traumas, contributing to an increased risk of peritonitis and sepsis (3).

Multidetector computed tomography (MDCT) imaging technology has grown rapidly in recent years, and is considered the gold standard in the diagnosis of blunt abdominal injuries, particularly solid organ injuries. Concerning bowel and mesenteric injuries, bowel-wall rupture, pneumoperitoneum, active extravasation, mesenteric stranding, and mesenteric hematoma are popular findings from MDCT scans (4).
Nevertheless, the role of this modality has still been mismatched in the diagnosis of bowel and mesenteric injuries in previous reports $(1,5,6)$. Additionally, the application of MDCT results in certain conditions in separating surgery from conservative therapy is also problematic (5). Our aim was to determine the diagnostic accuracy of 16-slice MDCT results in the diagnosis of bowel and mesenteric injuries, as well as the connection between these findings and treatment results.

\section{METHODS}

\section{Study Population}

The medical records and imaging studies of 86 patients (75 men and 11 women aged $4-76$ years old with a median age of 40.88 years), who were radiologically diagnosed with blunt bowel and mesenteric injuries using 16-slice MDCT scan and managed at our hospital during the period from June 2018 to 


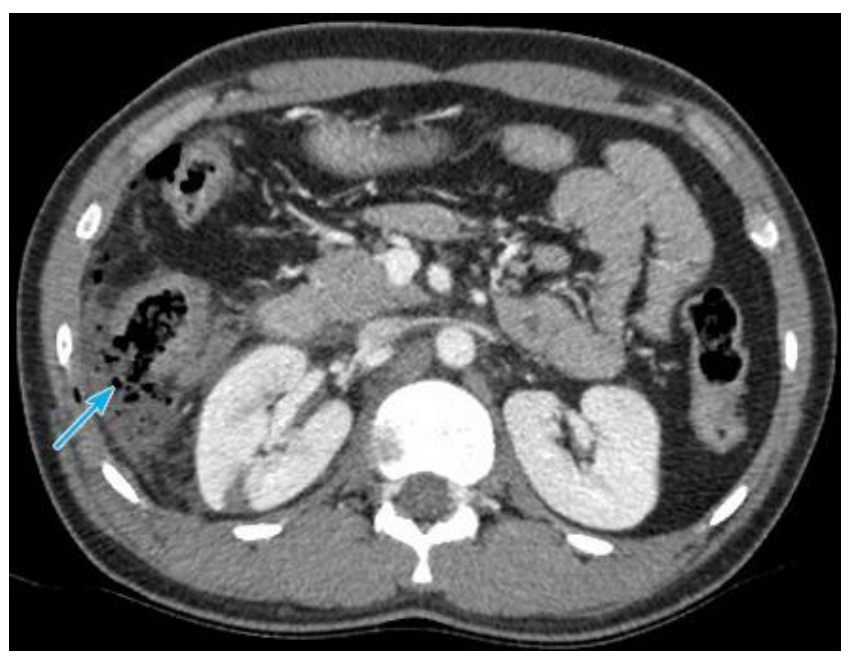

Figure 1. Bowel wall rupture in 21-year-old man. Axial 16-slice MDCT with contrast enhancement image shows the discontinuation of right colic flexure (arrow) and free- air and stranding surrounding. Laparotomy shows the hepatic colic flexure rupture and seromuscular tear of right colon.

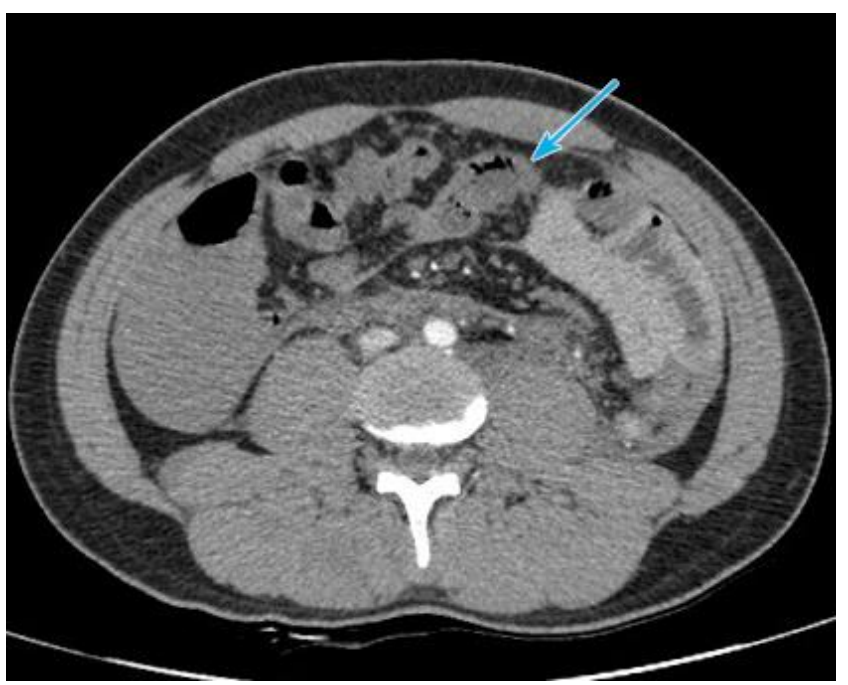

Figure 2. Reduced bowel wall enhancement in 27-year-old man. Axial 16-slice MDCT with contrast enhancement image shows decreased enhancement of the wall of small intestines (arrow) compared with those of adjacent bowel wall. Laparotomy shows large mesenteric tear leading to devascularization of jejunum.

July 2019, were retrospectively reviewed. The medical records included the site, type, and cause of injury, in addition to the associated injuries and treatment results. Ethical clearance was taken from the institute ethics committee with waiver of consent.

\section{MDCT Technique}

All studies were obtained on a 16-slice MDCT (Optima 2019, GE Healthcare System, Milwaukee, WI, USA) from the diaphragm to pubic symphysis with $350 \mathrm{mAs}$ and $120 \mathrm{kVp}$. Patients were supine. A multiphase 16-slice MDCT scan, including plain, arterial, and portal phases, was conducted by the same technique at $5 \mathrm{~mm}$ slice thickness, and reconstructed in the axial, coronal, and sagittal planes at $0.625 \mathrm{~mm}$ section thickness. An intravenous contrast agent (lobitridol, Xenetix 350 , Guerbet, Villepint, France) was administrated in a dose of $1.5 \mathrm{~mL} / \mathrm{kg}$ and at a rate of 3-5 mL/s using a power injector. The arterial and portal phases were initiated at 25-30s and 60-70s delay, respectively. An excretory phase (3-5 min) was performed in case blunt renal-collecting-system injury was suspected. No oral contrast was used in any case.

\section{Image Analysis}

Two radiologists (with 8 and 15 years of experience in abdominal-trauma imaging) retrospectively and independently read all examinations on a PACS workstation (Carestream PACS; Carestream Health, Eemnes, Netherlands) before surgical treatment. Any disagreement between them was resolved by consensus.

Each reader was asked to detect mesenteric and bowel signs that referred to blunt bowel and mesenteric injuries. Pneumoperitoneum was defined as free air within the peritoneal cavity and outside of the bowel (Figure 1). Reduced bowel-wall enhancement was confirmed when compared with that of the adjacent bowel wall (Figure 2). Janus sign was defined as a focal of increased-enhancement bowel loop adjacent to a focal decreased-enhancement one (6).

Bowel-wall thickening was defined as bowel-lumen thickness on the axial image over $10 \mathrm{~mm}$ for the stomach, over $3 \mathrm{~mm}$ for the small bowel, and over $5 \mathrm{~mm}$ for the cecum and colon (Figure 3) (7). Active extravasation was confirmed as the 


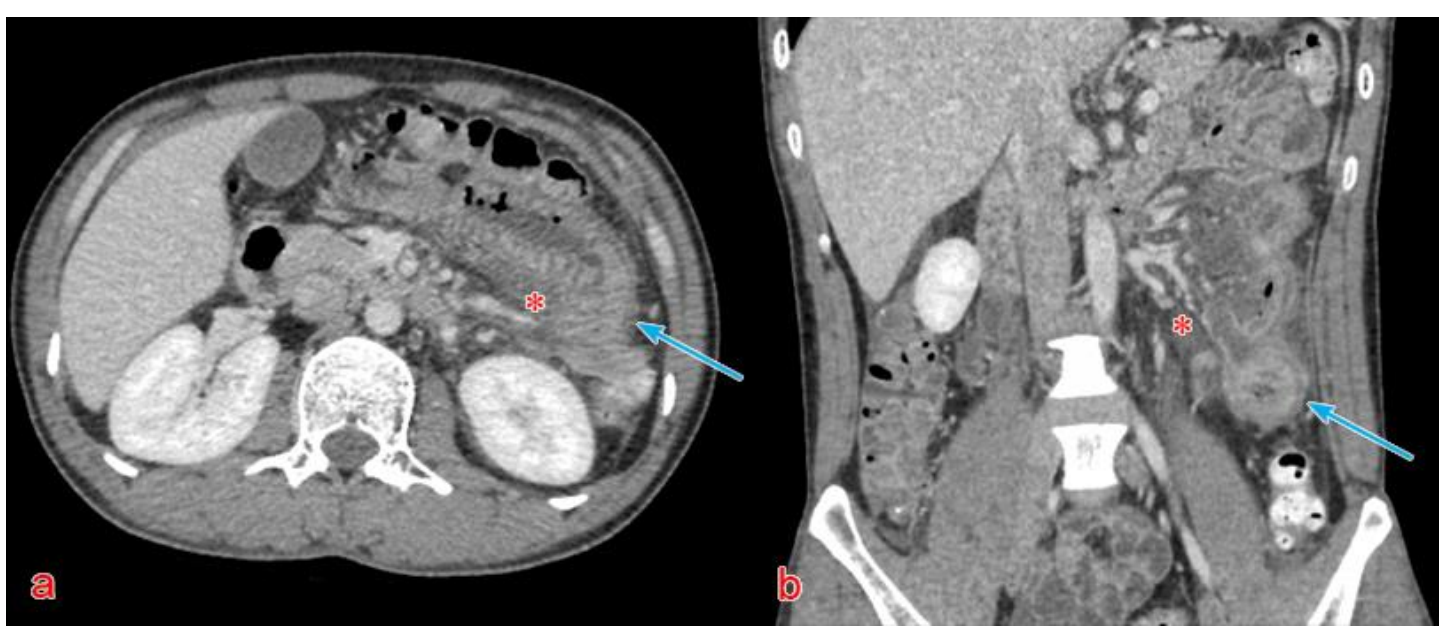

Figure 3. Bowel wall thickening in 37-year-old man. Axial (a) and coronal (b) 16-slice MDCT with contrast enhancement images show the bowel wall thickening (arrow), heterogenous enhancement of jejunum in left hypochondriac region, and adjacent mesenteric stranding (asterisk). Laparotomy shows three sites of jejunum's perforation, mesenteric tear without active bleeding and contusion in some jejunum loops.

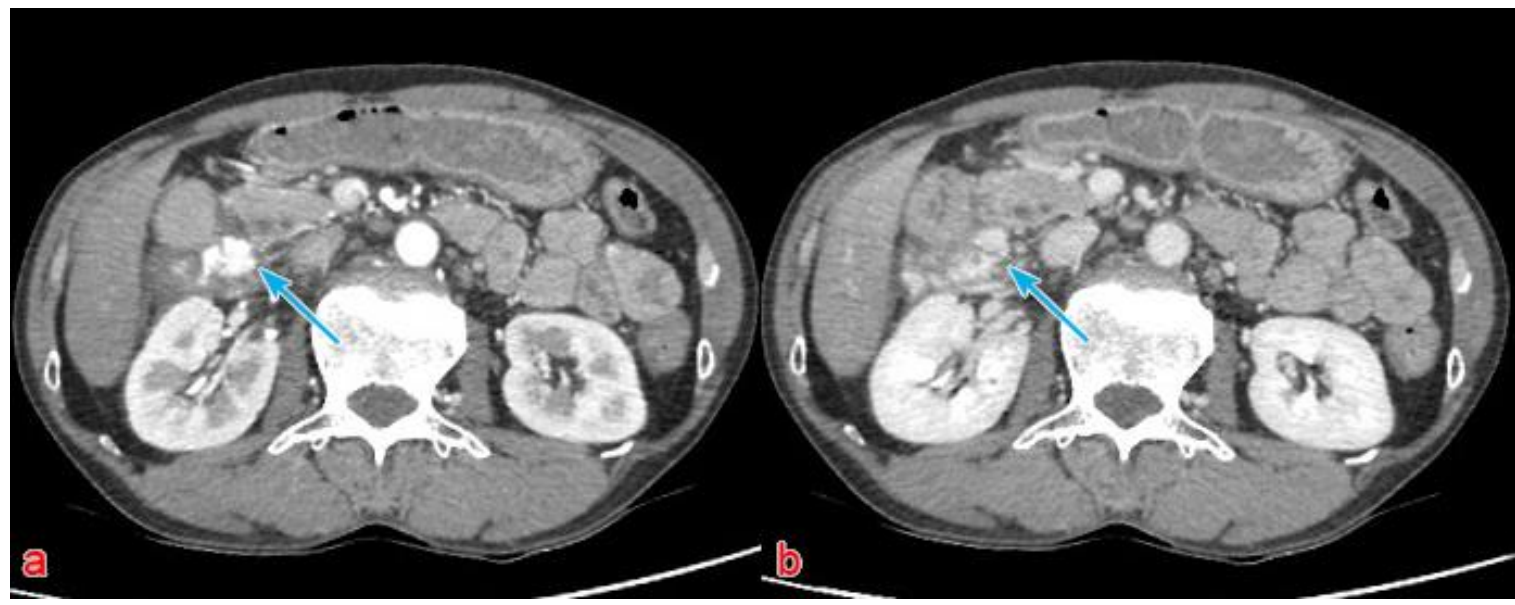

Figure 4. Active extravasation in a 53-year-old man. Axial 16-slice MDCT images at arterial (a), venous (b) phase, show the active extravasation appearing in the arterial phase and expanded in the venous phase (arrow) of pancreaticoduodenal artery. Laparotomy shows the mesenteric tear, active bleeding from anterosuperior pancreaticoduodenal artery and jejunum contusion.

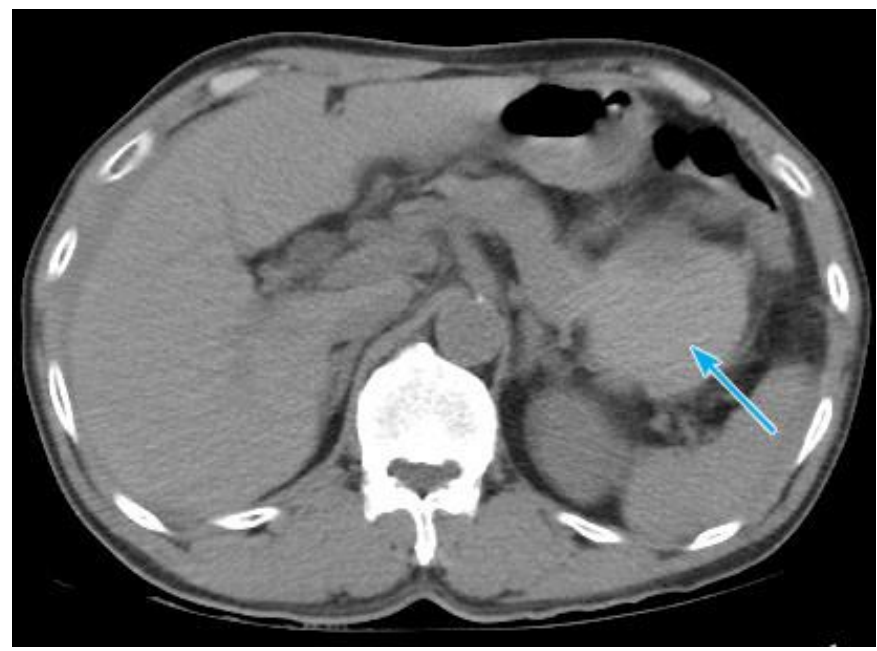

Figure 5. Mesenteric hematoma in 35-year-old man. Axial 16-slice MDCT with contrast enhancement image shows a focal hyperintensity fluid collection of mesenteries next to pancreatic tail (arrow). The patient was undergone conservative treatment.

appearance of extravasation in the arterial phase that extended into the venous phase (Figure 4) (8).

Mesenteric hematoma was defined as mesenteric fluid collection with hyperdensity extending from 50 to $70 \mathrm{HU}$ without enhancement after injection (Figure 5). Mesenteric stranding was considered if mesenteric fat had the density of soft tissue. 
Table 1. Main study-population characteristics

\begin{tabular}{|c|c|c|}
\hline Characteristics & Parameters & $\begin{array}{c}\mathrm{N} \\
\text { (percentage) } \\
\end{array}$ \\
\hline \multirow{3}{*}{$\begin{array}{l}\text { Accident types } \\
\quad(n=86)\end{array}$} & Traffic accident & $68(79.1 \%)$ \\
\hline & Work-related accident & $13(15.1 \%)$ \\
\hline & Other causes & $5(5.8 \%)$ \\
\hline \multirow{6}{*}{$\begin{array}{l}\text { Associated abdominal } \\
\text { injuries } \\
(\mathrm{n}=86)\end{array}$} & Spleen & $14(16.3 \%)$ \\
\hline & Liver & $24(27.9 \%)$ \\
\hline & Kidney & $13(15.1 \%)$ \\
\hline & Pancreas & $13(15.1 \%)$ \\
\hline & Bladder & $6(7.0 \%)$ \\
\hline & Other abdominal organs & $9(10.5 \%)$ \\
\hline \multirow{4}{*}{$\begin{array}{l}\text { Injury types } \\
\quad(n=68)\end{array}$} & Perforation & $56(82.4 \%)$ \\
\hline & Devascularization & $10(14.7 \%)$ \\
\hline & Seromuscular tear & $24(35.3 \%)$ \\
\hline & Mesenteric injury & $18(26.5 \%)$ \\
\hline \multirow{8}{*}{$\begin{array}{l}\text { Injury sites } \\
\quad(n=68)\end{array}$} & Stomach & $5(7.4 \%)$ \\
\hline & Duodenum & $8(11.8 \%)$ \\
\hline & Jejunum & $29(41.2 \%)$ \\
\hline & Ileum & $15(22.1 \%)$ \\
\hline & Cecum & $1(1.5 \%)$ \\
\hline & Appendix & $1(1.5 \%)$ \\
\hline & Colon & $13(19.1 \%)$ \\
\hline & Mesentery & $18(26.5 \%)$ \\
\hline
\end{tabular}

\section{Statistical Analysis}

SPSS version 22 was used to analyze data (IBM corp., Newyork, USA). Range and categorical variables were described as numbers and percentages. Diagnostic accuracy of each MDCT finding for the diagnosis of blunt bowel and mesenteric injuries was determined by sensitivity (Se), specificity (Sp), negative predictive value (NPV), positive predictive value (PPV), and accuracy (ACC). In this case, laparotomy findings were considered as a gold standard.

The association between MDCT findings and treatment strategy, including conservative treatment and laparotomy, was quantified by odds ratio (OR) and $95 \%$ confidence interval (CI) OR. The level of statistical significance was set at $p<0.05$. Inter-observer agreement for MDCT findings was defined with kappa coefficient $(\mathrm{k})$ statistics and measured as follows: $\mathrm{k}=0$ 0.2 , poor agreement; $k=0.21-0.4$, fair agreement; $k=0.41-0.6$, moderate agreement; $\mathrm{k}=0.61-0.8$, good agreement; and $\mathrm{k}=$ $0.81-1$, very good agreement.

\section{RESULTS}

\section{Study Population}

The main characteristics of the study population are shown in Table 1. The rate of traffic accidents related to motorcycle crashes was highest, at $79.1 \%$. All patients had associated injuries besides bowel and mesenteric injuries. Of the 68 patients who underwent laparotomy, 62 had findings of bowel and mesenteric injuries. In detail, 67 patients were operated on in the first $24 \mathrm{~h}$ after trauma. It is noted that one patient was initially diagnosed with bowel-wall contusion on a 16-slice MDCT scan and was treated conservatively. After $48 \mathrm{~h}$ of trauma, this patient was treated surgically due to an increase of clinical symptoms with a final diagnosis of jejunal rupture in the second MDCT scan. For the patient with bowel and mesenteric injuries confirmed with laparotomy, 34 cases had 1 site of injury, and 28 cases had 2 sites of injury.
Table 2. Diagnostic accuracy of computed tomography (16slice MDCT) findings

\begin{tabular}{cccccc}
\hline 16-slice MDCT findings & Se\% & Sp\% & PPV\% & NPV\% & ACC\% \\
\hline Bowel-wall rupture & 28.57 & 100 & 100 & 23.07 & 41.18 \\
\hline Active extravasation & 28.57 & 98.15 & 80 & 84.13 & 83.82 \\
\hline Janus sign & 38.33 & 87.50 & 95.83 & 15.91 & 50.00 \\
\hline Bowel-wall thickening & 70.00 & 62.50 & 93.33 & 21.74 & 69.12 \\
\hline Reduced bowel-wall enhancement & 15.00 & 100 & 100 & 13.56 & 25.00 \\
\hline Pneumoperitoneum & 83.33 & 75.00 & 96.15 & 37.50 & 82.35 \\
\hline Mesenteric hematoma & 17.46 & 80.00 & 91.67 & 7.14 & 22.06 \\
\hline Mesenteric stranding & 75.81 & 50.00 & 94.00 & 16.67 & 73.53 \\
\hline
\end{tabular}

Se: sensitivity; Sp: Specificity; PPV: positive predictive value; NPV: negative predictive value; ACC: accuracy

Table 3. Association between 16-slice MDCT findings and treatment results

\begin{tabular}{ccccc}
\hline 16-slice MDCT findings & $\boldsymbol{p}$ value & OR & $\mathbf{9 5 \%} \mathbf{C l}$ & $\mathbf{~}$ \\
\hline Bowel-wall rupture & $0.03^{*}$ & 7.34 & $1.004-58.82$ & 0.839 \\
\hline Active extravasation & 0.57 & 1.59 & $0.168-14.92$ & 0.883 \\
\hline Janus sign & $0.008^{*}$ & 6.49 & $1.39-30.30$ & 0.582 \\
\hline Bowel-wall thickening & 0.317 & 1.78 & $0.68-4.65$ & 0.851 \\
\hline Reduced bowel-wall enhancement & 0.27 & 6.41 & $0.47-32.26$ & 0.675 \\
\hline Pneumoperitoneum & $<0.001^{\star}$ & 29.41 & $7.46-111.11$ & 1.000 \\
\hline Mesenteric hematoma & 0.548 & 0.65 & $0.21-2.00$ & 0.629 \\
\hline Mesenteric stranding & $0.03^{*}$ & 2.90 & $1.07-7.87$ & 0.614 \\
\hline
\end{tabular}

* Statistically significant; OR: Odds ratio; $\mathrm{Cl}$ : confidence interval; $\mathrm{k}$ : Kappa coefficient

\section{Diagnostic Accuracy of MDCT Findings}

Diagnostic accuracy of MDCT findings in the diagnosis of blunt bowel and mesenteric injuries is shown in Table 2. Bowel-wall rupture, active extravasation, and reduced bowel enhancement were the findings that had low sensitivity but high specificity of $100 \%, 98.15 \%$, and $100 \%$, respectively. Pneumoperitoneum had the highest sensitivity of $83.33 \%$ and specificity of $75 \%$. Active extravasation and pneumoperitoneum were findings with the highest accuracy of $83.82 \%$ and $82.35 \%$ respectively. Free fluid was observed in all cases.

\section{Association between 16-slice MDCT Findings and Treatment Results}

The association between 16-slice MDCT findings and treatment results is shown in Table 3. Findings of bowel-wall rupture $(p=0.03)$, Janus sign $(p=0.008)$, pneumoperitoneum $(p<0.001)$, and mesenteric stranding $(p=0.03)$ on CT scan had significant correlation with surgical treatment. The presence of these findings increased the possibility of implementing surgical treatment 7-, 6-, 29-, and 3-fold, respectively. Interobserver agreement was very good for bowel-wall rupture, active extravasation, and pneumoperitoneum findings; good for reduced bowel-wall enhancement, mesenteric hematoma, and mesenteric stranding findings; and moderate for Janus sign findings.

\section{DISCUSSION}

Due to the overlapping presence of other viscus trauma or subtle imaging characteristics, bowel and mesenteric injuries pose diagnostic challenges for physicians and radiologists. Unfortunately, due to delayed diagnosis, complications such 
as hemorrhage or peritonitis contribute to a high risk of morbidity and mortality (9-11). MDCT performance recorded in several previous studies was reasonably efficient, with sensitivity ranging from $69 \%$ to $95 \%$ and specificity ranging from $94 \%$ to $100 \%$ in the identification of bowel and mesenteric lesions $(4,12,13)$. Our results showed that male patients were overwhelming with a rate of $87.21 \%$, and most accidents were triggered by traffic accidents. The same rates were reported by Atri et al. (7), and Elton et al. (12). Blunt bowel and mesenteric injuries are often present and can be misdiagnosed in multiple simultaneous accidents (2). The study of Nance et al. showed that the incidence of hollow-organ injury is proportionately raised with the number of injured solid organs (14). In the present study, in addition to bowel and mesenteric injuries, all patients had associated injuries. Alternation between fixed and flexible parts of the small intestine is prone to shearing power, which renders this system a frequent site of bowel injury (15). Our study showed that the jejunum was the most common site of bowel injuries, followed by the ileum, with a rate of $41.2 \%$ and $22.1 \%$, respectively.

Bowel-wall rupture was considered as a direct finding of blunt bowel injury, and active extravasation suggested that an active bleeding condition has high specificity of $100 \%$ and $98.15 \%$ and low sensitivity of $28.57 \%$ and $28.57 \%$, respectively. Our result was comparable to those reported in the previous studies, which confirmed that these characteristics are not highly sensitive $(7,8,11)$. Since bowel-wall rupture frequently occurs at the antimesenteric side of bowel loops, it could be misdiagnosed on a MDCT scan if its size is small (16). Similarly, a small vessel tear could be occulted by mesenteric hematoma (8). Nonetheless, a finding of active extravasation should be taken into consideration as an indication for simultaneous surgery $(4,5)$. Reduced bowel-wall enhancement may represent an ischemic bowel due to the rupture of supplied arteries or arterial occlusions (12). In our study, this feature had a sensitivity of $15 \%$, which was lower than that reported by Faget et al. (8), and higher than the result reported by Atri et al. (7); it also had specificity of $100 \%$, which was in line with findings that reported by these authors.

In our 10 patients with surgically proven ischemic bowels, one patient had pneumatosis portalis and one patient had active extravasation on MDCT scan in addition to reduced bowel-wall enhancement. Pneumoperitoneum was, according to previous studies, a highly specific indication for intestinal perforation but it could contribute to a false-positive diagnosis of bowel perforation $(4,11,17)$. In our study, this finding had a sensitivity and specificity of $83.33 \%$ and $75 \%$, respectively. There were three cases that showed no bowel perforation on laparotomy in spite of presented pneumoperitoneum in the MDCT scan. This disagreement may be because those patients also had intraperitoneal bladder rupture, and free air may have originated from the Foley catheter insertion procedure. Free intraperitoneal air can also be induced by pneumothorax, diaphragm disruption or mechanical ventilation (18).

Bowel-wall thickening, mesenteric hematoma, mesenteric stranding, and free fluid are indirect findings of blunt bowel and mesenteric injuries. The sensitivity and specificity of these findings were differently described in previous studies $(5,7,8)$. Mirvis et al. stated that free fluid and bowel-wall thickening were unspecific findings that might be present in cases of hypovolemic shock in the setting of the trauma, particularly associated with liver or splenic injuries (19). Our study showed that free fluid was present in all cases, and the specificity of bowel-wall thickening was $62.5 \%$. The study of Steenburg et al. suggested that bowel-wall thickening, mesenteric stranding, and free fluid were findings of mesenteric contusion or seromuscular, tear and could be treated conservatively (11). Nevertheless, four patients in our study that showed bowelwall thickening and mesenteric stranding on MDCT scan had bowel perforation on laparotomy. Hence, these features may be suggestive signs of peritonitis that is essential to indicate surgical treatment.

Bowel-wall rupture and pneumoperitoneum findings on MDCT scan had significant correlation with surgical treatment, with an OR of 7.34 (95\% Cl 1.004-58.82) and 29.41 (95\% Cl 7.46111.11 ), respectively. Faget et al. stated that these two findings were enough to confirm the presence of surgical intervention, with an OR of 128.9 (95\% Cl 9.5-999.9) and 140.5 (95\% Cl 9.3999.9), respectively (8). Furthermore, in our study, interobserver agreement of these two findings was very good $(\mathrm{k}=$ 0.839 and 1.00 , respectively), which is similar to a report done by LeBedis et al (20). Our study also manifested that two other MDCT findings that have significant correlation with surgical treatment were Janus signs and mesenteric stranding. The rate of surgical intervention would be raised 6- and 3-fold, respectively, with the presence of these findings. The study of Cho et al. reported that $75 \%$ of patients with bowel transection showed a Janus sign near the site; therefore, it might be considered as a specific sign of bowel injury (6). With regards to mesenteric stranding, several studies showed that this feature was high sensitive but low specific to mesenteric injury $(1,4)$. Steenburg et al. did not find statistically significant difference in mesenteric-stranding size for the surgical versus conservative treatment of bowel injury (11). Nonetheless, the combination of active extravasation and mesenteric-stranding findings was predictive of surgical intervention, as reported by Faget et al. (8).

There are some limitations in this clinical study. First this study had small sample size and was performed at single center. In addition, we did not assess the correlation between the quantitative surgical parameters and MDCT findings. Moreover, we lacked the comparison with a healthy group. In this study, we only focused on the bowel and mesentery injury without deeply investigating other associated injuries. Thus, further studies should be performed to validate our findings.

\section{CONCLUSIONS}

Our study showed that the most significant MDCT results for the treatment and prognosis of blunt bowel and mesenteric injuries are bowel-wall rupture and pneumoperitoneum. Bowel-wall rupture was the definitive symptom of bowel injury and had considerable association with surgical treatment, while pneumoperitoneum was an unspecific indication of blunt bowel injury; however, urgent intervention would be required when this is detected. Certain MDCT results serve a persuasive function and should be paired with clinical tests in order to make them viable.

\section{Ethical Approval and Declaration of Patient Consent}

Institutional review board of Viet Duc Hospital approved this retrospective study. Informed consent of patients was waived. 


\section{REFERENCES}

1. Bates DD, Wasserman M, Malek A, Gorantla V, Anderson SW, Soto JA, et al. Multidetector CT of Surgically Proven Blunt Bowel and Mesenteric Injury. Radiographics. 2017;37:613 25. https://doi.org/10.1148/rg.2017160092 PMid:28165875

2. Gad MA, Saber A, Farrag S, Shams ME, Ellabban GM. Incidence, patterns, and factors predicting mortality of abdominal injuries in trauma patients. N Am J Med Sci. 2012;4:129-34. https://doi.org/10.4103/1947-2714.93889 PMid:22454826 PMCid:PMC3309620

3. Fakhry SM, Brownstein M, Watts DD, Baker CC, Oller D. Relatively short diagnostic delays ( $<8$ hours) produce morbidity and mortality in blunt small bowel injury: an analysis of time to operative intervention in 198 patients from a multicenter experience. J Trauma. 2000;48:408-14. https://doi.org/10.1097/00005373-200003000-00007 PMid:10744277

4. Brofman N, Atri M, Hanson JM, Grinblat L, Chughtai T, Brenneman F. Evaluation of bowel and mesenteric blunt trauma with multidetector CT. Radiographics. 2006;26:1119-31. https://doi.org/10.1148/rg.264055144 PMid: 16844935

5. Scaglione M, de Lutio di Castelguidone E, Scialpi M, Merola $\mathrm{S}$, Diettrich Al, Lombardo $\mathrm{P}$, et al. Blunt trauma to the gastrointestinal tract and mesentery: is there a role for helical CT in the decision-making process? Eur J Radiol. 2004;50:67-73. https://doi.org/10.1016/j.ejrad.2003.11.016 PMid: 15093237

6. Cho HS, Woo JY, Hong HS, Park MH, Ha HI, Yang I, et al. Multidetector CT findings of bowel transection in blunt abdominal trauma. Korean J Radiol. 2013;14:607-15. https://doi.org/10.3348/kjr.2013.14.4.607 PMid:23901318 PMCid:PMC3725355

7. Atri M, Hanson JM, Grinblat L, Brofman N, Chughtai T, Tomlinson G. Surgically important bowel and/or mesenteric injury in blunt trauma: accuracy of multidetector CT for evaluation. Radiology. 2008;249:52433. https://doi.org/10.1148/radiol.2492072055 PMid: 18796660

8. Faget C, Taourel P, Charbit J, Ruyer A, Alili C, Molinari N, et al. Value of $C T$ to predict surgically important bowel and/or mesenteric injury in blunt trauma: performance of a preliminary scoring system. Eur Radiol. 2015;25:3620-8. https://doi.org/10.1007/s00330-015-3771-7 PMid:25991477

9. Robbs JV, Moore SW, Pillay SP. Blunt abdominal trauma with jejunal injury: a review. J Trauma. 1980;20:308-11. PMid:7365836
10. Snyder WH, 3rd, Weigelt JA, Watkins WL, Bietz DS. The surgical management of duodenal trauma. Precepts based on a review of 247 cases. Arch Surg. 1980;115:422-9. https://doi.org/10.1001/archsurg.1980.01380040050009 PMid:7362449

11. Steenburg SD, Petersen MJ, Shen C, Lin H. Multi-detector CT of blunt mesenteric injuries: usefulness of imaging findings for predicting surgically significant bowel injuries. Abdom Imaging. 2015; 40: 1026-1033. https://doi.org/10.1007/s00261-014-0262-2 PMid:25296995

12. Elton C, Riaz AA, Young N, Schamschula R, Papadopoulos B, Malka V. Accuracy of computed tomography in the detection of blunt bowel and mesenteric injuries. Br J Surg. 2005;92:1024-8. https://doi.org/10.1002/bjs.4931 PMid: 15931660

13. Breen DJ, Janzen DL, Zwirewich CV, Nagy AG. Blunt bowel and mesenteric injury: diagnostic performance of $C T$ signs. J Comput Assist Tomogr. 1997;21:706-12. https:/doi.org/ 10.1097/00004728-199709000-00005 PMid:9294556

14. Nance ML, Peden GW, Shapiro MB, Kauder DR, Rotondo MF, Schwab CW. Solid viscus injury predicts major hollow viscus injury in blunt abdominal trauma. J Trauma. 1997;43:618-22. https://doi.org/10.1097/00005373-199710 000-00009 PMid:9356057

15. Hawkins AE, Mirvis SE. Evaluation of bowel and mesenteric injury: role of multidetector CT. Abdom Imaging. 2003;28:505-14. https://doi.org/10.1007/s00261-002-00792 PMid:14580093

16. Okino Y, Kiyosue H, Mori H, Komatsu E, Matsumoto S, , et al. Root of the small-bowel mesentery: correlative anatomy and CT features of pathologic conditions. Radiographics. 2001;21:1475-90. https://doi.org/10.1148/radiographics. 21.6.g01nv121475 PMid:11706218

17. Hamilton P, Rizoli S, McLellan B, Murphy J. Significance of intra-abdominal extraluminal air detected by $\mathrm{CT}$ scan in blunt abdominal trauma. J Trauma. 1995;39:331-3. https://doi.org/10.1097/00005373-199508000-00023 PMid:7674403

18. Brody JM, Leighton DB, Murphy BL, Abbott GF, Vaccaro JP, Jagminas $L$, et al. CT of blunt trauma bowel and mesenteric injury: typical findings and pitfalls in diagnosis. Radiographics. 2000;20:1525-36. https://doi.org/10.1148/ radiographics.20.6.g00nv021525 PMid:11112806

19. Mirvis SE, Gens DR, Shanmuganathan K. Rupture of the bowel after blunt abdominal trauma: diagnosis with $\mathrm{CT}$. AJR Am J Roentgenol. 1992;159:217-21. https://doi.org/ 10.2214/ajr.159.6.1442385 PMid:1442385

20. LeBedis CA, Anderson SW, Bates DD, Khalil R, Matherly D, Wing $\mathrm{H}$, et al. CT imaging signs of surgically proven bowel trauma. Emerg Radiol. 2016;23:213-9. https://doi.org/ 10.1007/s10140-016-1380-7 PMid:26873603 